\title{
HYGROTHERMAL AGEING OF REPROCESSED POLYLACTIDE
}

\author{
J.D. Badia, L. Santonja-Blasco, A. Martínez-Felipe, A. Ribes-Greus*
}

This is an open-access version, according to http://www.sherpa.ac.uk/romeo/issn/0141-3910

Full text available at https://www.sciencedirect.com/science/article/pii/S0141391012002169

DOI: https://doi.org/10.1016/j.polymdegradstab.2012.06.001

Please, cite it as:

Badia, J. D., Santonja-Blasco, L., Martínez-Felipe, A., Ribes-Greus, A. (2012). Hygrothermal ageing of reprocessed polylactide. Polymer degradation and stability, 97(10), 1881-1890.

Instituto de Investigación en Tecnología de Materiales.

Universidad Politécnica de Valencia,

Camino de Vera s/n 46071 Valencia, Spain

*To whom correspondence should be addressed.

Corresponding author. Fax: +34963879817

E-mail address: aribes@ter.upv.es 


\title{
HYGROTHERMAL AGEING OF REPROCESSED POLYLACTIDE
}

\author{
J.D. Badia, L. Santonja-Blasco, A. Martínez-Felipe, A. Ribes-Greus*
}

\author{
Instituto de Tecnología de Materiales (ITM), \\ Universitat Politècnica de València \\ Camino de Vera s/n, E-46022 Valencia, Spain \\ ${ }^{*}$ Corresponding author: A. Ribes-Greus
}

+34 963879817

e-mail: aribes@ter.upv.es 


\title{
HYGROTHERMAL AGEING OF REPROCESSED POLYLACTIDE
}

\author{
J.D. Badia, L. Santonja-Blasco, A. Martínez-Felipe, A. Ribes-Greus*
}

\begin{abstract}
The influence of an accelerated hygrothermal ageing simulation test on a commercial PLA and its three subsequent mechanically-reprocessed materials was studied. The analysis was focused on the water diffusion kinetics and the physico-chemical changes induced by the hygrothermal degradation. Water diffusion proceeded faster than chain relaxation processes, as defined by a Case II absorption model. It was proved that the water diffusion rate decreased with subsequent reprocessing cycles and increased with higher hygrothermal ageing temperatures. Hydrolytic chain scission provoked significant molar mass decays and consequent general losses of thermal and mechanical performance. The rearrangement into crystalline fractions of shorter chains provoked by hygrothermal ageing was qualitatively and quantitatively followed by both Fourier-Transform Infrared Spectroscopy and Differential Scanning Calorimetry. The microstructural changes were monitored by the cold-crystallization temperature, the crystallinity degree $X_{C}$ and the absorbance intensity ratio $I_{921} / I_{955}$. A Weibull model showed that the crystallites were formed faster at higher reprocessing cycles and at lower hygrothermal ageing temperatures. All these effects were particularly significant for PLA reprocessed more than one time.
\end{abstract}

\section{Keywords}

Polylactide (PLA)

Hygrothermal ageing

Water absorption kinetics

Crystallinity

Differential Scanning Calorimetry (DSC)

Fourier-Transform Infrared Analysis (FT-IR) 


\section{Introduction}

The current research focused on bio-based materials due to their features of coming from renewable resources and being biodegradable after their service lives has brought new possibilities for potential application fields, such as the packaging and the agricultural sectors. In this sense, poly (lactic acid) or polylactide (PLA) is an outstanding candidate to replace commodity polymers, due to its good processability, mechanical properties, thermal stability and low environmental impact [1-2]. However, its introduction into the market would therefore represent an upcoming new main source of polymeric waste, which should be handled as a new commodity. To explore the potential of enlarging its service life during further uses, by recovering it thus obtaining an added value from its discard remains a challenge. Among all recovery methods [3], material valorisation by mechanical recycling is widely established for commodities [4-12]. Recent studies have been focused on the study of the effects of reprocessing on PLA performance [13-19].

The reported studies of hygrothermal ageing on PLA generally describe their behaviours under human-body simulated conditions [20-23], due to its early use in bio-absorbable sutures or as controlled-release drug-carrier. The impact of hygrothermal ageing on PLA will depend on the relative kinetics of water diffusion and chain-segments mobility [24]. The main effects of water in the polymer morphology are physical modifications, such as plasticization, and chemical reactions, such as hydrolysis [25]. The extent of the influence of these effects on PLA performance may depend upon different factors of both the ageing conditions, such as temperature, as well as PLA features, such as molar mass, chemical structure or crystallinity. Thus, in order to warranty the durability on PLA goods, and for extension, of its recyclates, the previous knowledge about the influence of the degrading agents on their macromolecular properties is necessary. In this sense, hygrothermal ageing at high relative humidity and temperatures stands out as an accelerated procedure to simulate the behaviour of polymers [26]. Therefore, the purpose of this work was three-fold: firstly, to evaluate the influence of temperatures above the glass transition on the kinetics of water absorption of PLA materials; secondly, to monitor the physico-chemical changes undergone in the materials during hygrothermal ageing; and finally, to assess the influence of the synergetic thermo-mechanical and hygrothermal degradations on hydro-saturated materials in terms of molar mass, mechanical and thermal performance. 


\section{Experimental procedure}

\subsection{Material. Reprocessing simulation.Sample preparation.}

Polylactide (PLA) 2002D, a thermo-forming grade PLA, was obtained from Natureworks LLC (Blair, NE) as pellets, provided by AIMPLAS (Paterna, Spain). Prior to processing, virgin PLA (VPLA) pellets were dried during $2 \mathrm{~h}$ at $80{ }^{\circ} \mathrm{C}$ in a dehumidifier Conair Micro-D FCO 1500/3 (UK), in order to remove surface humidity. Afterwards, the samples were processed by means of injection moulding with an Arburg 420 C 1000-350 (Germany) injector, single-screw model (diameter $\Phi=35 \mathrm{~mm}$, length $/ \Phi=23$ ). Temperature gradient set from hopper to nozzle was 160 , 170, 190, 200 and $190^{\circ} \mathrm{C}$. Moulds were set at $15^{\circ} \mathrm{C}$. Cooling time residence was $40 \mathrm{~s}$ and total residence time 60s. Samples were dried before each processing cycle. After injection, a fraction of the samples was kept as test specimens and the rest was ground by means of a cutting mill Retsch SM2000 (UK), which provided pellets of size $\mathrm{d}<20 \mathrm{~mm}$ to be fed back into the process. Up to three processing cycles were applied under the same conditions to obtain the different testing specimens of reprocessed PLA (RPLA-i, with i: 1-3). 1 mm thick prismatic probes for hygrothermal ageing tests were obtained from compression moulding, as described elsewhere [27].

\subsection{Hygrothermal ageing conditions}

A normalised water absorption test reported in the ISO 62 - method 1 [28] was adopted as hygrothermal ageing environment, modifying the temperature specifications to the desired ageing conditions. Initially, the specimens were dried at $50{ }^{\circ} \mathrm{C}$ in a vacuum oven during $24 \mathrm{~h}$, and then kept in a desiccator at normalized lab conditions according to ISO 291[29]. Samples of VPLA and RPLA-i were submerged into distilled water at three different temperatures - 65, 70 and $75{ }^{\circ} \mathrm{C}$ - above the glass transition and below the cold-crystallization of VPLA and RPLA-i [17]. After certain periods of time, the specimens were removed from water, gently wiped to get rid of surface moieties, then weighed and finally submerged back into water. The average content of absorbed water was calculated by quintuplicate by weigh difference, as reported in the ISO 62.

\subsection{Analytical monitoring of hygrothermal ageing}

\subsubsection{Fourier-Transform Infrared Analysis - Attenuated Total Reflection (FT-IR)}

FT-IR spectra were collected by a Thermo Nicolet 5700 FT-IR Spectrometer (MA, USA), previously calibrated, and equipped with a single-reflection Smart Orbit accessory for attenuated total reflection (ATR) measurements, with diamond crystal. 32 co-added spectra 
were recorded for each specimen at a resolution of $4 \mathrm{~cm}^{-1}$ with a spacing of $1 \mathrm{~cm}^{-1}$, from 4000 to $600 \mathrm{~cm}^{-1}$ of wavenumber. The spectra were characterized with the aids of the software OMNIC 7.0 from Thermo Scientific. Presented spectra correspond to the average of each individual analysis, with baseline correction. At least 8 measurements in different positions of the material were performed, to assure representative results.

\subsubsection{Differential Scanning Calorimetry (DSC)}

DSC analyses were carried out by a Mettler Toledo DSC 822 instrument (Columbus, OH) calibrated with indium and zinc standards. Approximately $5 \mathrm{mg}$ of pellets were placed in $40 \mu \mathrm{L}$ aluminium pans, which were sealed and pierced to allow the $\mathrm{N}_{2}$ gas flow $\left(50 \mathrm{ml} \cdot \mathrm{min}^{-1}\right)$. A 10 ${ }^{\circ} \mathrm{C} \cdot \mathrm{min}^{-1}$ heating rate was employed in the temperature range between $0{ }^{\circ} \mathrm{C}$ and $200{ }^{\circ} \mathrm{C}$. DSC analysis was performed with the aid of the software STAR $^{\mathrm{e}} 9.10$ from Mettler-Toledo. The samples were characterized at least by triplicate and the averages of temperatures and enthalpies were taken as representative values.

\subsection{Determination of performance of saturated samples}

\subsubsection{Molar mass determination}

The molar mass of saturated samples was assessed by capillary viscometry. The reduced $\eta_{\text {red }}$ and inherent $\eta_{\text {inh }}$ viscosities were recorded by quintuplicate by means of a Cannon-Fleske capillary viscometer type at $30{ }^{\circ} \mathrm{C}$, with the use of $99.9 \%$ analytical grade tetrahydrofurane (THF) supplied by Sigma-Aldrich as solvent, being $\eta_{s p}=\eta_{r e l}-1$ and $\eta_{r e l}=t \cdot t_{0}{ }^{-1}$, where $t$ and $t_{0}$ were the times (s) of flowing of the dissolution and solvent, respectively, and $c=0.4 \mathrm{~g} \cdot \mathrm{dL}^{-1}$ the concentration of the dissolution. The intrinsic viscosity $[\eta]$, usually measured by the use of the intersection of Huggins (Eq 1) and Kraemer (Eq 2) linear expressions, was performed according to a single-point measurement, since $k_{1}-k_{2}$ approached 0.5, and thus [30]Eq 3 could be directly used.

$\frac{\eta_{s p}}{c}=[\eta]+k_{1}[\eta]^{2} c$

$$
\begin{aligned}
& \frac{\llbracket \ln \left(\eta \rrbracket_{r e l}\right)}{c}=[\eta]+k_{2}[\eta]^{2} c \\
& {[\eta]=\frac{\left.\left(2\left(\eta_{s p}-\ln \llbracket \eta_{r e l}\right)\right)\right]^{\frac{1}{2}}}{c}}
\end{aligned}
$$


The viscosity molar mass values $M_{V}$ was then calculated with the well-known Mark-Houwink equation $[\eta]=K \cdot M_{V}{ }^{\alpha}$, with constants $K=1.74 \cdot 10^{-4} \mathrm{dL} \cdot \mathrm{g}^{-1}$ and $\alpha=0.763$ [31] .

\subsubsection{Mechanical properties}

Dynamic Mechanical Thermal Analyses were conducted in dual cantilever clamping with 10 $\mathrm{mm}$ of effective length between clamps, with the three point bending mode, by means of a Rheometric Scientifics Dynamic-Mechanical-Thermal Analyser Mark IV (USA). The displacement was checked before all the experiments. The deformation force was set at $0.01 \mathrm{~N}$. Experiments at $1 \mathrm{~Hz}$ were carried out on heating from $35^{\circ} \mathrm{C}$ to $145^{\circ} \mathrm{C}$ with isothermal steps of $2^{\circ} \mathrm{C}$. Analyses were performed at least three times per sample to ensure reproducibility.

\subsubsection{Thermal stability}

Thermogravimetric experiments were carried out by means of a Mettler-Toledo TGA/SDTA 851 (Columbus, $\mathrm{OH}$ ). Samples weighing $\sim 5 \mathrm{mg}$ were placed in an alumina holder with capacity for $70 \mu \mathrm{L}$ and heated from 25 to $750{ }^{\circ} \mathrm{C}$ at a heating rate of $10^{\circ} \mathrm{C} \cdot \mathrm{min}^{-1}$, under constant flow of $50 \mathrm{~mL} \cdot \mathrm{min}^{-1}$ of Argon. Experiments were repeated at least three times, and the averages were considered as representative values.

\section{Results and discussion}

\subsection{Phenomenological assessment of hygrothermal ageing}

Fig 1 shows the percentage of water absorption $M_{t}$ for virgin and reprocessed PLAs at the three hygrothermal aging temperatures $T_{H A}$ chosen for the study. Similar profiles were described by all samples, showing a one-step mass-uptake with characteristic rapid water absorption followed by an asymptotic saturation, where no more water was absorbed by the polymer matrices. The values of the saturation masses $M_{S}$, along with their relative variations for given $T_{H A}$ and reprocessing steps are gathered at Table $\mathbf{1}$.

Due to the effect of reprocessing and the hygrothermal ageing temperature, the saturation point $M_{S}$ was reached by all RPLA-i at earlier times and lower values of water absorption than those given by VPLA.

At a given hygrothermal ageing temperatures $T_{H A}$, the saturation point $M_{S}$ generally showed relative decreases of $~ 12-16 \%$ from VPLA to RPLA-1, 4-13\% from RPLA-1 to RPLA-2, and 2.6-6 \% from RPLA-2 to RPLA-3, being this effect reproducible at any $T_{H A}$. After the 
maximum number of reprocessing steps, the water uptake was reduced by $>24.6 \%$, regardless the temperature.

At a given processing step, the saturation point $M_{S}$ was considerably reduced by increasing the hygrothermal ageing temperature. For instance in the case of RPLA-1, there was a relative $\sim 21$ $\%$ reduction in $M_{S}$ from $65^{\circ} \mathrm{C}$ to $70^{\circ} \mathrm{C}$, being the value decreased by a $\sim 37 \%$ from $70{ }^{\circ} \mathrm{C}$ to 75 ${ }^{\circ} \mathrm{C}$. Similar relative decreases in $M_{S}$ were found for VPLA and the successive recyclates. Between 65 and $75{ }^{\circ} \mathrm{C}$, the $M_{S}$ was reduced by $>50 \%$ for all materials.

\section{Figure 1- Table 1}

The properties of the different reprocessed PLA at the different hygrothermal ageing temperatures were affected, as shown by the changes in molar mass, thermal stability and mechanical performance:

(i) The viscosity molar mass $M_{V}$ was calculated with the aim of assessing the degradation extent on the polymer structures. Fig 2 shows reductions of the viscous molar mass $M_{V}$ of the RPLA-i samples, respect to VPLA, which can be interpreted as a consequence of chain scission due to both reprocessing and hygrothermal aging. At higher hygrothermal ageing temperatures, the reduction on the viscous molar mass $M_{V}$ was more acute and the effect of previous reprocessing erased.

(ii) The mechanical performance was evaluated by Dynamical-Mechanical Thermal analyses (DMTA) in bending mode, taking into account the mechanical stress $\Delta E^{\prime}$, i.e. the jump of storage modulus between the glassy and the rubbery state, as described elsewhere [17]. Fig 3 shows that the higher the hygrothermal ageing temperature was applied, the lower the $\Delta E$ ' were obtained, in addition to the previous degradation stage due to reprocessing [17].

(iii) Finally, the thermal performance was characterized by means of Thermogravimetric analyses (TGA). A one-stage decomposition profile was described by all samples, as shown elsewhere [18]. The peak degradation temperature $T_{P}$ of the firstderivative thermogravimetric curve was considered for the analysis. Despite reprocessing did not affect the $T_{p}$ in a great extend, a general reduction was found (Fig 4) for all materials along the increase of hygrothermal ageing temperature, due to the synergetic hydrolytic and thermal degradation.

Fig 2,3,4

\subsection{Water uptake kinetics}


In order to further study the effect of reprocessing and the influence of the hygrothermal ageing temperature on the kinetics of water uptake, Eq 4 was applied, where $M_{t} \cdot M_{s}^{-1}$ stands for the fractional mass uptake and $k$ and $n$ are constants [32]. Shortly, this expression accounts for the theoretical description of the shape of the sorption curve, and classifies the kinetics into three different categories, according to the value of the power $n$ [24] and was proposed by Alfrey et al as a means for classifying the different types of diffusion kinetics. Generally, three classes can be distinguished, which can be associated to the relative rates of penetrant diffusion and polymer relaxation: (i) if $n=1 / 2$, the Case I or Fickian model is followed, where the rate of penetrant diffusion is slower than that of the polymer relaxation; (ii) on the contrary, if $n=1$, the Case II absorption model explains that the diffusion is very rapid if compared to relaxation; (iii) if $n$ is between $1 / 2$ and 1 , there is not limiting factor and the behaviour is termed as 'anomalous'.

$\frac{M_{t}}{M_{S}}=k \cdot t^{n}$

Fig 5 shows the reduced plot of water uptake for virgin and reprocessed PLAs for $T_{H A}=65^{\circ} \mathrm{C}$. Analogous plots were observed for the rest of the experiments performed at 70 and $75{ }^{\circ} \mathrm{C}$. A region of slower water absorption is visible in the curves of VPLA and RPLA-1, ranging between the initial Fickian region and saturation [32]. The analysis of the double logarithmic plot (Eq 5) at short times was useful for the description of kinetics. The results of the linear fittings for all materials at different $T_{H A}$ are summarized in Table 2.

$\log \left(\frac{M_{t}}{M_{S}}\right)=\log k+n \cdot \log (t)$

Most of the cases exhibit $n$ values near 1, which coincides with the Case II absorption model [24] suggesting that the initial diffusion was very rapid if compared to relaxation phenomena. It should be pointed out that nor the number of reprocessing cycles neither the hygrothermal ageing temperature modified the behaviour, which indicated that above the glass transition of the materials, the chain relaxation processes eased the diffusion of water into the matrices.

Figure 5-Table 2

Once classified the type of diffusion followed by VPLA and its successive recyclates, the influence of reprocessing on the diffusion rates at each hygrothermal ageing temperature $T_{H A}$ was aimed. Considering a mass uptake into a plane sheet and unidirectional flow and constant diffusion coefficient, a numerical solution to the general expression of Fick's law is obtained in Eq 6 [32-33]. 
$\frac{M_{t}}{M_{S}}=8 \cdot\left(\frac{D \cdot t}{L^{2}}\right)^{\frac{1}{2}} \cdot\left[\pi^{-\frac{1}{2}}+2 \cdot \sum_{m=0}^{\infty}(-1)^{m} \cdot \operatorname{ierf}\left(\frac{m \cdot L}{4 \cdot(D \cdot t)^{\frac{1}{2}}}\right)\right]$

, where $L$ is the thickness of the sample, which is twice the length of the pathway of diffusion, $m$ is an integer counter and ierf is the integral of the error function. The expression can be simplified if the analysis is focused on the data at short times, where the diffusion is more relevant. Thus, Eq 7 is deduced:

$\frac{M_{t}}{M_{S}} \approx \frac{8}{\pi^{\frac{1}{2}}} \cdot\left(\frac{D \cdot t}{L^{2}}\right)^{\frac{1}{2}}$

The diffusion coefficient was obtained from the slope of the linear fitting of $M_{t} \cdot M_{S}^{-1} \mathrm{Vs} t^{1 / 2} \cdot L^{-1}$ and it is shown in Fig 5. The higher the reprocessing steps were applied, the lower $D$ ruled the water uptake into the polymeric matrices (Fig 6). Conversely, the higher $T_{H A}$ the hygrothermal ageing was carried out at, the higher $D$ were obtained, thus the faster the water saturated the polymer matrices.

Finally, the activation energy Ea related to an Arrhenius-like dependence of the diffusion rate with the temperature was obtained from the slope of the linear fitting of $\ln D$ vs $T^{-1}$. The values $\left(\mathrm{kJ} \cdot \mathrm{mol}^{-1}\right)$ were $74 \pm 5,89 \pm 7,93 \pm 6$ and $97 \pm 4$, for VPLA, RPLA-1, RPLA-2 and RPLA-3, respectively. This increasing tendency was in agreement with the reduction of $D$ values, since higher $E a$ would imply more difficulty to diffuse water along the matrix in reprocessed samples, thus in correlation with lower velocities.

Although one might consider that the release of lactic acid might play a role in the diffusion of water and subsequent hydrolytic behaviour of PLA., Tsuji et al [34] showed that the hydrolytic behaviour was similar in a wide $\mathrm{pH}$ range, from neutral to very acid conditions $(\mathrm{pH}=2)$.

\section{Figure 6}

The presence of water into the polymer matrices may influence the microstructure affecting to the final properties of the material, both by plasticization of the amorphous fraction and/or by hydrolytic chain scission reactions that may promote a faster formation of crystalline domains. These changes may thus influence the diffusion behaviour of PLA. Consequently, the variations in the microstructure were analytically monitored by FT-IR and DSC. 


\subsection{Monitoring of microstructure evolution by FT-IR and DSC}

The formation of crystalline domains during the water absorption process was initially monitored by FT-IR, due to its non-destructive character and its versatility to obtain reliable and fast results. The observation of the relative variation of the peaks located at wavenumbers 921 $\mathrm{cm}^{-1}$ and $955 \mathrm{~cm}^{-1}$ corresponding to the coupling of the C-C backbone stretching with the C- $\mathrm{H}_{3}$ rocking modes, which are related to the presence of $\alpha$-crystalline and amorphous regions [35], respectively, is shown in Fig 7 for the case of virgin PLA tested at $70{ }^{\circ} \mathrm{C}$. Similar plots were shown by the subsequent reprocessed PLAs at all tested temperatures. The band located at 921 $\mathrm{cm}^{-1}$ increased along with the decrease of the band centred at $955 \mathrm{~cm}^{-1}$ suggesting and advance on the formation of $\alpha$-crystals.

\section{Figure 7}

In order to compare quantitatively the evolution of the crystalline domains for the different tested materials and temperatures, the relative intensity indexes $I_{921} / I_{955}$ were represented along the reduced time $\tau_{\mathrm{HA}}$, being $\tau_{\mathrm{HA}}(\%)=t \cdot t_{e}^{-1} \cdot 100$, where $t$ is the time counter and $t_{e}$ is the time at the end of the experiment, in order to obtain comparable curves. Fig 8 shows the evolution of $I_{921} / I_{955}$ for virgin PLA and its subsequent recyclates for all the hygrothermal ageing temperatures $T_{\text {HA. }}$. A Weibull-like [36] fashion could describe (Eq 9) the evolution of $I_{921} / I_{955}$ along the experiment. Fitting FT-IR procedures were performed by a Levenberg-Marquardt algorithm [37-38] to adjust the parameter of the fitting values in the iterative procedure, which results are gathered in Table 3. Generally, a reduction of the power $p$ and an increase of the constant $c$ are indicative of acceleration in the crystallization process at earlier times. Actually, it was shown that due to effect of reprocessing, the formation of crystalline domains was favoured. This effect was expected, since the presence of shorter chains due to the thermomechanical degradation suffered during reprocessing might ease the rearrangement into lamellar structures. Concerning the effect of temperature, it was shown that raising the $T_{H A}$ did not accelerate the formation of crystalline domains, but on the contrary, it was decelerated.

$\left.\frac{I_{921}}{I_{955}}\left(\tau_{H A}\right)=\frac{I_{921}}{I_{955}}(1)-\left(\frac{I_{921}}{I_{955}}(1)-\frac{I_{921}}{I_{955}}(0)\right) \cdot e^{-\left(c-\tau_{H A}\right.}\right)^{p}$

Figure 8 - Table 3 
The morphological changes promoted by ageing were further studied by Differential Scanning Calorimetry DSC. Fig 9 shows the first calorimetric heating scan of virgin and reprocessed PLAs at all tested hygrothermal ageing temperatures $T_{H A}$ and reduced times $\tau_{H A}$. It should be noticed that the presence or disappearance of transitions occurred gradually in a different manner for each polymer, highlighting the effect of the previous thermo-mechanical degradation induced by recycling. For example, in the case of $70^{\circ} \mathrm{C}$, the profile shown by the DSC trace of VPLA at $\tau_{H A}=50 \%$, was similar to that of RPLA1 at $\tau_{H A}=16 \%$, and those of RPLA2 and RPLA3 at $\tau_{H A}=8 \%$. Analogous profile evolutions were shown at all $T_{H A}$. Such results suggested that the morphological changes of PLA could be ascribed to superimposed effects considering different combinations of processing history, i.e. thermo-mechanical degradation, and temperature of hygrothermal ageing.

In order to monitor the effect of both reprocessing and $T_{H A}$, the analysis was focused on three different regions, corresponding to the characteristic transitions of PLA, namely, a glass transition from 30 to $80^{\circ} \mathrm{C}$, an exothermal cold-crystallization from $80^{\circ} \mathrm{C}$ to nearly $140{ }^{\circ} \mathrm{C}$, and an endothermic melting from $140{ }^{\circ} \mathrm{C}$ to almost $160^{\circ} \mathrm{C}$. Note that both cold-crystallization and melting merge in many cases and thus the separation given in temperature ranges is valid for guidance. The DSC traces were characterized by means of the peak temperature of the endothermic relaxation superimposed to the glass transition $T_{G-P}$, cold-crystallization $T_{C C}$ and melting $T_{m}, T_{m s}$ temperatures, gathered in Table 4, and the crystallinity degree (Eq 10), which evolution is given in Fig 10, being:

$X_{C}=\frac{\Delta \boldsymbol{h}_{m}-\left|\boldsymbol{\Delta} \boldsymbol{h}_{C C}\right|}{\Delta h_{m}^{0}} \cdot 100$

, where $\boldsymbol{\Delta} \boldsymbol{h}_{m}$ is the endothermal melting enthalpy, $\boldsymbol{\Delta} \boldsymbol{h}_{C C}$ the cold-crystallization enthalpy and $\Delta h_{m}^{0}$ the melting enthalpy of a $100 \%$ crystalline PLA, assumed as $93.1 \mathrm{~J} \cdot \mathrm{g}^{-1}$ [39].

Figs 9-10, Table 4

Particularly, the analysis performed at each region provided remarkable results:

(i) Concerning the study on the glass transition region, the $T_{G-P}$ showed a decrease of 4 to $6{ }^{\circ} \mathrm{C}$ along with a diminution of the associated enthalpy as longer hygrothermal ageing times $\tau_{H A}$ were reached, which was indicative of the plasticizing effect of water. 
(ii) With regards to the cold-crystallization, the $T_{C C}$ was generally displaced to lower temperatures, indicating the presence of shorter chains as longer times $\tau_{\text {HA }}$ of hygrothermal ageing were reached. The intervals of temperatures decreased by $T_{C C}$ were more significant for the reprocessed PLAs than those given by the virgin material. After a certain time, the coldcrystallization was not visible anymore, probably due to the threshold of potential crystallinity of each sample had been reached, that is, because all the regions available for crystallisation were already crystallised during ageing and degraded chains were too short to rearrange. The presence of shorter chains after reprocessing and at longer hygrothermal ageing may inhibit the formation of crystalline structures, as supported below.

(iii) The melting curve behaved in accordance to the cold-crystallization, since the peak temperature $T_{m}$ slightly moved between 1 and $3{ }^{\circ} \mathrm{C}$ towards higher values. Conversely to what described by the evolution of $T_{C C}$, the intervals of temperatures increased by $T_{m}$ were less significant for the reprocessed PLAs than those given by the virgin material. In addition, the appearance [40] of a small melting peak $T_{m s}$ around $140{ }^{\circ} \mathrm{C}$ was observed at high $\tau_{\mathrm{HA}}$, which was likewise displaced to higher temperatures as the exposure to the hygrothermal ageing was higher. This effect is also indicative of reduction of chain length due to degradation.

(iv) The increase of crystallinity degree was indicative of the formation of crystalline domains and thus of previous chain scissions processes occurred during not only the thermo-mechanical degradation due to reprocessing [17], but also during the hygrothermal ageing at which the samples were subjected in this study. The profiles shown in Fig $\mathbf{1 0}$ present a similar shape than that shown by the relative intensity indexes $I_{921} / I_{955}$ given in Fig 8, and thus were fitted to a Weibull model, analogue to Eq 9, and given in Eq 11.The results of the fitting are gathered in Table 5. The results are in accordance to those described during the FT-IR analysis, since a general increase of the $c$ and a reduction of the power $p$ were found for increasing reprocessing cycles and for decreasing hygrothermal ageing temperatures. Accordingly, the formation of crystals was experienced faster at $65{ }^{\circ} \mathrm{C}$ than at 70 or $75{ }^{\circ} \mathrm{C}$, and faster in the fashion RPLA3>RPLA-2>RPLA-1>VPLA at all $T_{H A}$. This effect could be ascribed to the competitive effect between the rearrangement of polymer chains into crystals on the one hand, and the water diffusion process on the other hand. As indicated by the significant increase of the diffusion coefficients with $T_{H A}$, the matrices were saturated quicker at higher $T_{H A}$ and thus the formation of crystalline domains may be somehow modified by the effect of a more severe chain scission at higher temperatures. The presence of scissored chains might reduce the capability of water absorption of the materials, as well as the formation of permanent crystalline fractions at the 
saturated samples. In fact, as can be seen in Fig 10, the maximum of $X_{C}$ reached at $65{ }^{\circ} \mathrm{C}$ ( 35\%) was higher than that found at $70^{\circ} \mathrm{C}(\sim 30 \%)$ or $75^{\circ} \mathrm{C}(\sim 27 \%)$.

$X_{C}\left(\tau_{H A}\right)=X_{C}(1)-\left(X_{C}(1)-X_{C}(0)\right) \cdot e^{-\left(c-\tau_{H A}\right)^{p}}$

\section{Table 5}

Summing up, the study of the hygrothermal degradation in terms of chain scission must take into account two contributions: on the one hand, those provoked by reprocessing (before hygrothermal ageing) and on the other hand, those activated by temperature (during hygrothermal ageing) . Concretely:

(i) At a given temperature, reprocessing induced chain scission processes $\left(T_{C C} \downarrow\right)$, reducing the capability of water absorption of RPLA-i ( $M_{S} \downarrow$, Fig 1- Table 1). The reorganization of cleaved chains into crystalline domains was found to be faster for higher reprocessed materials ( $c \uparrow, p \downarrow$, Fig 10). Accordingly, the diffusion rate of water throughout the polymeric matrices was decreased ( $D \downarrow$, Fig 6 ) to similar values for RPLA-i regardless the temperature, in connection with the almost equal values of $X_{C}$ at saturation.

(ii) For a certain reprocessed material, the increase of the temperature of hygrothermal ageing $T_{\text {HA }}$ promoted the thermal activation of the diffusion process ( $D \uparrow$, Fig 6). This in turn, provoked further chain scission (apparition of $T_{C C}$ at higher $\tau_{H A}$ for the same material, Fig 9-Table 4), which stressed the diminution of water absorption capability $\left(M_{S} \downarrow\right.$, Fig 1-Table 1) and decelerated the formation of permanent crystalline fractions ( $c \downarrow, p \uparrow$, Fig 10), being the crystallinity degree at saturation $X_{C}$ thus reduced

\section{Conclusions}

The application of normalized water absorption experiments was useful to simulate and monitor the degradation induced by accelerated hygrothermal ageing on virgin and reprocessed PLA at temperatures above the glass transition. The degradation was confirmed in terms of molar mass decrease, due to the chain scission reactions promoted by temperature, provoking a general loss in thermal and mechanical performance.

The kinetics of water uptake followed by all materials was described by a Case II absorption model, which stated that the diffusion of water was faster than the rate of polymer chain relaxation. Reprocessing provoked a decrease of the water diffusion rate, which was contrarily increased with the temperature of the hygrothermal ageing. 
The presence of water into the polymer matrices displaced the glass transition towards lower temperatures due to plasticization of the polymer matrices. As well, hydrolytic chain scissions occurred, being more remarkable for reprocessed PLA and higher temperatures. Consequently, a decrease in the saturation point was found for increasing reprocessing cycles and increasing hygrothermal ageing temperatures. The application of two Weibull-like models concluded that the formation of crystals was accelerated with higher reprocessing cycles but contrarily retarded with increasing the temperature of ageing. This fact was related to the additive effect of the chain scission processes occurred during reprocessing and those subsequently provoked by hygrothermal ageing.

The effects of hygrothermal ageing were particularly significant for PLA reprocessed more than one time and for increasing temperatures 


\section{References}

1. Tsuji H,Doi Y, editors.Biopolymers.Polyesters III.Applications and commercial Products.Steinbüchel.Weinheim : Wiley-VCH VerlagGMbh, 2002.

2. Auras R, Harte S, Selke S. An overview of polylactides as packaging materials. Macromolecular Bioscience 2004; 4: 835-864.

3. Al-Salem S M, Lettieri P, Baeyens J. Recycling and recovery routes of plastic solid waste (PSW): A review. Waste management 2009; 29: 2625-2643.

4. Strömberg E, Karlsson S. The design of a test protocol to model the degradation of polyolefins during recycling and service life. Journal of Applied Polymer Science 2009; 112: 1835-1844.

5. Vilaplana F, Ribes-Greus A, Karlsson S. Degradation of recycled high-impact polyestyrene .Simulation by reprocessing and thermo-oxidation. Polymer Degradation and Stability 2006; 91: 2163-2170.

6. Vilaplana F, Karlsson S,Ribes-Greus A. Changes in the micro-structure and morphology of highimpact polystyrene subjected to multiple processing and thermo-oxidative degradation. EuropeanPolymerJournal2007; 43: 4371-4381.

7. Badia JD,Vilaplana F, Karlsson S, Ribes-Greus A. Thermal analysis as a quality tool for assessing the influence of thermo-mechanical degradation on recycled poly(ethylene terephthalate). Polymer Testing 2009; 28: 169-175.

8. La Mantia F, Vinci M. Recycling poly(ethylene terephthalate). Polymer Degradation and Stability1994; 45: 121-125.

9. Torres N, Robin J J,Boutevin, B. Study of thermal and mechanical properties of virgin and recycled poly(ethylene terephthalate) before and after injection molding. EuropeanPolymerJournal2000; 36: 20752080.

10. Badia JD, Strömberg E, Ribes-Greus A, Karlsson S.A statistical design of experiments for optimizing the MALDI-TOF-MS sample preparation of polymers. An application in the assessment of the thermomechanical degradation mechanisms of poly(ethylene terephthalate). AnalyticaChimicaActa2011; 692: 85-95.

11. Badia JD, Strömberg E, Karlsson S, Ribes-Greus A. The role of crystalline, mobile amorphous and rigid amorphous fractions on the performance of recycled poly (ethylene terephthalate) (PET).Polymer Degradation and Stability 2012; 97: 98-107.

12. Nait-Ali LK, Colin X, Bergeret A. Kinetic analysis and modelling of PET macromolecular changes during its mechanical recycling by extrusion.Polymer Degradation and Stability 2011; 96: 236-246.

13. Zenkiewicz M, Richert J, Rytlewsky P, Moraczewski K, Stepczynska M, Karasiewicz T. Characterisation of multi-extruded poly(lactic acid). Polymer Testing 2009; 28: 412-418.

14. Pillin I,Montrelay N,Bourmaud A,Grohens Y. Effect of thermo-mechanical cycles on the physicochemical properties of poly(lactic acid). Polymer Degradation and Stability 2008; 93: 321-328. 
15. Carrasco F; Pagès P; Gámez-Pérez J; Santana OO, Maspoch ML. Processing of poly(lactic acid): Characterization of chemical structure, thermal stability and mechanical properties. Polymer Degradation and Stability 2010; 95: 116-125.

16. Badía J.D., Strömberg E, Ribes-Greus A, Karlsson S. Assessing the MALDI-TOF MS sample preparation procedure to analyze the influence of thermo-oxidative ageing and thermo-mechanical degradation on poly (lactide). European Polymer Journal 2011;47: 1416-1428

17. Badia JD, Strömberg E, Karlsson S, Ribes-Greus A. Material valorisation of amorphous polylactide. Influence of thermo-mechanical degradation on the morphology, segmental dynamics, thermal and mechanical perfomance. Polymer Degradation and Stability 2012;97: 670-678.

18. Badia JD, Santonja-Blasco L, Martínez-Felipe A, Ribes-Greus A. A methodology to assess the energetic valorization of bio-based polymers from the packaging industry: Pyrolysis of reprocessed polylactide. Bioresource Technology, 2012; 111: 468-475

19. Badia JD, Santonja-Blasco L, Martínez-Felipe A, Ribes-Greus A. Reprocessed polylactide: Studies of thermo-oxidative decomposition. Bioresource Technology, 2012; 114: 622-628

20. ProikakisCS, MamouzelosNJ, TarantiliPA, AndreopoulosAG.Swelling and hydrolytic degradation of poly(D,L-lactic acid) in aqueous solutions. Polymer Degradation and Stability 2006, 91: 614-619.

21. SahaSK, Tsuji H. Effects of molecular weight and small amounts of D- lactide units on hydrolytic degradation of poly(L-lactic acid)s. Polymer Degradation Stability 2006; 91: 1665-1673.

22. Wiggins JS, Hassan MK, Mauritz KA, Storey RF. Hydrolytic degradation of poly(D,L-lactide as a function of end group: carboxylic acid vs. hydroxyl. Polymer 2006; 47: 1960-1969.

23. de PaulaEV.,Mano V, Pereira FV.Influence of nanowhiskers on the hydrolytic degradation behavior of poly(D,L-lactide).Polymer Degradation and Stability 2011; 96:1631-1638.

24. Alfrey, T. Chemical Engineering News 1956; 43:64.

25. Hiljanen-Vainio M, Varpomaa P, Seppälä J, Törmälä P. Modification of poly(L-lactides) by blending: mechanical and hydrolytic behaviour. Macromolecular Chemistry and Physics 1996; 86: 1892-1898.

26. Berthé V,Ferry L, Bénéze tJC, Bergeret A. Ageing of different biodegradable polyesters blends mechanical and hygrothermal behavior. Polymer Degradation and Stability 2010; 95: 262-269.

27. Santonja-Blasco L, Moriana R, Badía JD, Ribes-Greus A. Thermal analysis applied to the characterization of degradation in soil of polylactide: I. Calorimetric and viscoelastic analyses.Polymer Degradation and Stability 2010; 95: 2185-2191.

28. ISO62:2008. Plastics- Determination of water absorption.

29. ISO 291:1997. Plastics - standard atmospheres for conditioning and testing.

30. SanchesNB, DiasML, PachecoEBAV. Comparative techniques for molecular weight evaluation of poly(ethylene terephthalate) (PET). Polymer Testing 2005; 24: 688-693.

31. Dorgan, JR., Janzen J, Knauss D M., Hait S B., Limoges B R., Hutchinson M H. Fundamental solution and single-chain properties of polylactides. Journal of Polymer Science Part B: Polymer Physics 2005; 43: 3100-3111.

32. Neogi P, ed. Diffusion in Polymers. New York:Marcel Dekker Inc, 1996 
33. Crank J, ed. The mathematics of Diffusion.Oxford:Clarendon Press, 1975.

34- Tsuji H, Nakahara K. Poly(L-lactide). IX. Hydrolysis in acid media. Journal of applied Polymer Science. 2002; 86: 186-194.

35. Kister G, Cassanas G, Vert M. Effects of morphology, conformation and configuration on the IR and Raman spectra of various poly(lacitc acid)s. Polymer 1998; 39: 267-272.

36. Weibull W.A statistical distribution function of wide applicability, Journal of applied MechanicsTransactions ASME 1951; 18: 293-297.

37. Levenberg K. A method for solution of certain non-linear problems in least squares.Quaterly of Applied Mathematics 1944; 2: 164-168.

38. Marquardt D. W.An algorithm for the least-squares estimation of non-linear parameters. SIAM Journal of Applied Mathematics, 1963; 11: 431-441.

39. Fischer EW, Sterzel HJ, Wegner G. Investigation of the structure of solution grown crystals of lactide copolymers by means of chemical reactions. Kolloid ZZ Polymer 1973;251:980-90 .

40. Yasuniwa M, Tsubakihara S, Sugimoto Y, Nakafuku C. Thermal Analysis of the Double-Melting Behavior of Poly(L-lactic acid). Journal of Polymer Science: Part B: Polymer Physics, 2004; 42:25-32 


\section{Acknowledgements}

B.Sc. Oscar Gil-Castell is acknowledged for his dedication in the lab and his outstanding attitude towards learning. The authors thank the Spanish Ministry of Science and Innovation, through the Research Projects ENE2011-28735-C02-01 and UPOVCE-3E-013, the Ministry of Education and Science for the awarding of the FPI pre-doctoral grant to L. Santonja-Blasco and FPU pre-doctoral grants to A. Martinez-Felipe and J.D. Badía. The financial support of the Generalitat Valenciana, through the Grisolia (A. Martinez-Felipe) and Forteza (J.D. Badia) programs and the ACOMP/2011/189. UPV is thanked for additional support through the PAID 05-09-4331 program and the PAID 04-11 for the allowance conceded to attend to the III International Conference on Biodegradable and Biobased Polymers (BIOPOL2011) in Strasbourg. 


\section{Captions to figures}

Fig 1. Water uptake profiles for virgin and reprocessed PLAs at different hygrothermal ageing temperatures.

Fig 2. Evolution of viscous molar mass of saturated samples, in comparison to those of nondegraded samples, for virgin and reprocessed PLAs at all hygrothermal ageing temperatures.

Fig 3. Evolution of mechanical stresses of saturated samples, in comparison to those of nondegraded samples, for virgin and reprocessed PLAs at all hygrothermal ageing temperatures.

Fig 4. Evolution of peak decomposition temperatures of saturated samples, in comparison to those of non-degraded samples, for virgin and reprocessed PLAs at all hygrothermal ageing temperatures.

Fig 5. Reduced water uptake plot of virgin PLA submitted to hygrothermal ageing at $65^{\circ} \mathrm{C}$. Inset: detail of double-logarithmic plot for the kinetic analysis and fitting to Eq. (5).

Fig 6.Evolution of the water diffusion rate for virgin and reprocessed PLAs at all hygrothermal ageing temperatures, obtained after Eq. (7).

Fig 7. Evolution of infrared bands corresponding to the coupling of the C-C backbone stretching with the $\mathrm{C}-\mathrm{H}_{3}$ rocking modes, related to the presence of $\alpha$-crystalline $\left(921 \mathrm{~cm}^{-1}\right)$ and amorphous $\left(955 \mathrm{~cm}^{-1}\right)$ regions, for the case of virgin PLA at $70^{\circ} \mathrm{C}$, at all reduced hygrothermal ageing times.

Fig 8. Evolution of the relative intensity indexes of the bands located at $921 \mathrm{~cm}^{-1}$ (crystalline) and $955 \mathrm{~cm}^{-1}$ (amorphous) for virgin and reprocessed PLAs at all hygrothermal ageing temperatures. Symbols: experimental results. Lines: Fitted Weibull fashions- Eq. (9).

Fig 9. DSC traces of the monitoring of the hydrolysis and crystalline formation for virgin and reprocessed PLA and hygrothermal ageing temperatures. Numbers (from 0 to 100 correspond to the respective reduced hygrothermal ageing times).

Fig 10.Evolution of the crystallinity degree for virgin and reprocessed PLAs at all hygrothermal ageing temperatures. Symbols: experimental results. Lines: Fitted Weibull fashions -Eq (11). 
Badia, J. D., Santonja-Blasco, L., Martínez-Felipe, A., Ribes-Greus, A. (2012). Hygrothermal ageing of reprocessed polylactide. Polymer degradation and stability, 97(10), 1881-1890.

\section{FIGURE 1}
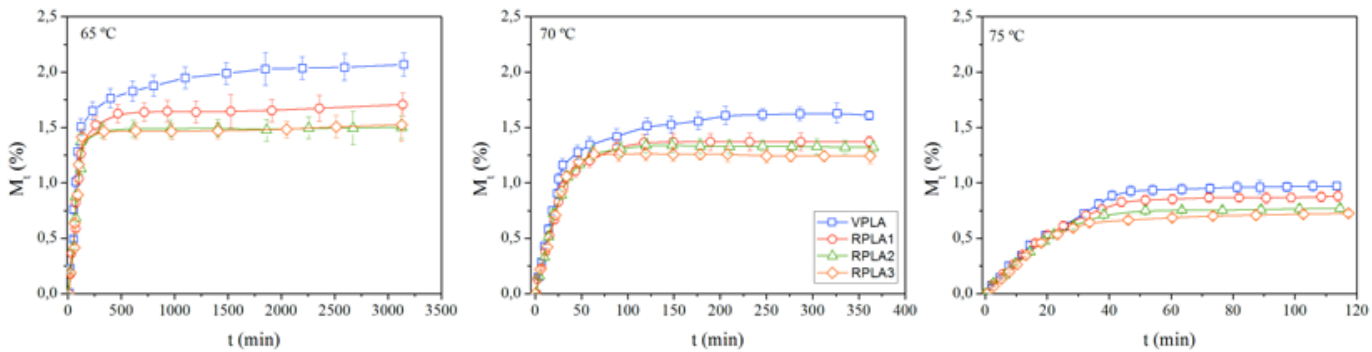
FIGURE 2

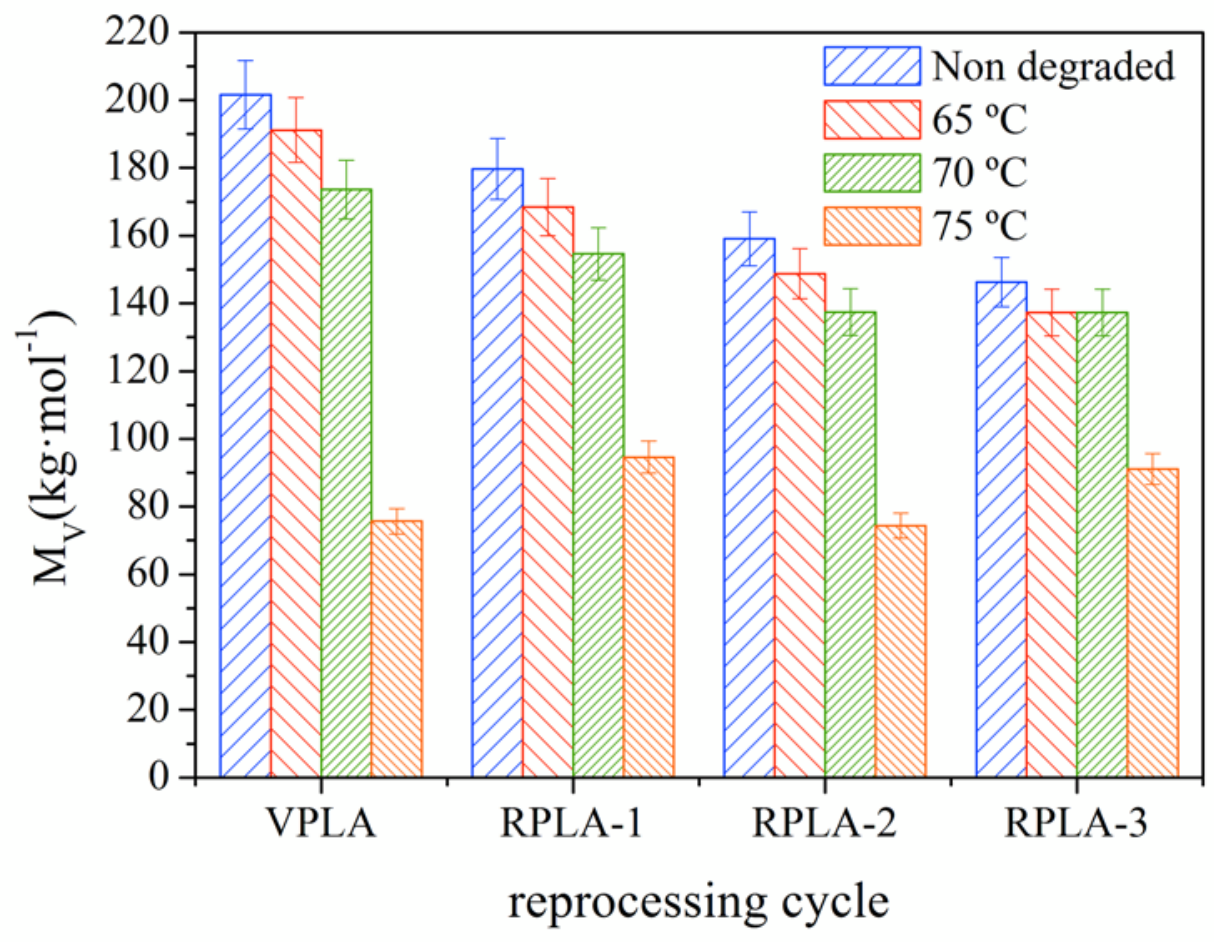


FIGURE 3

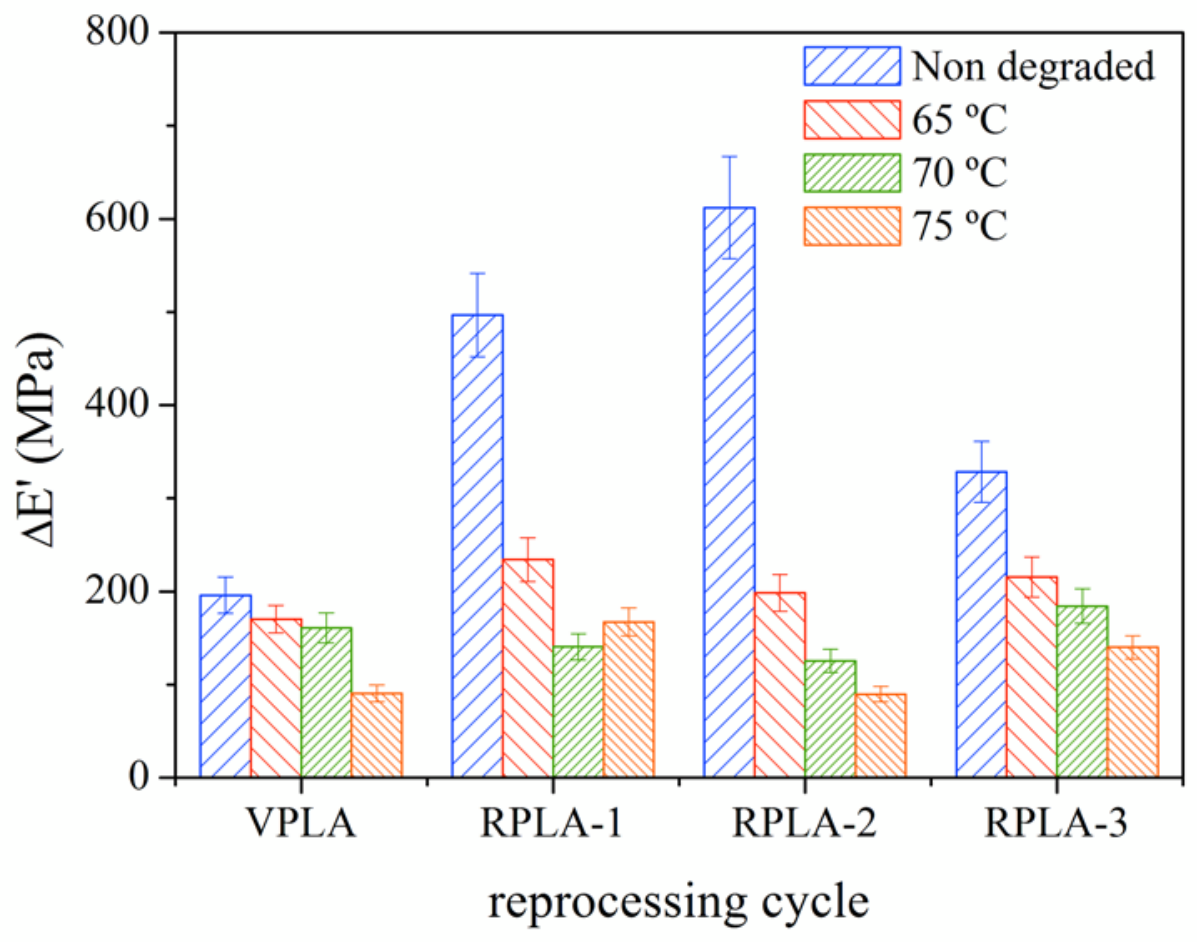




\section{FIGURE 4}

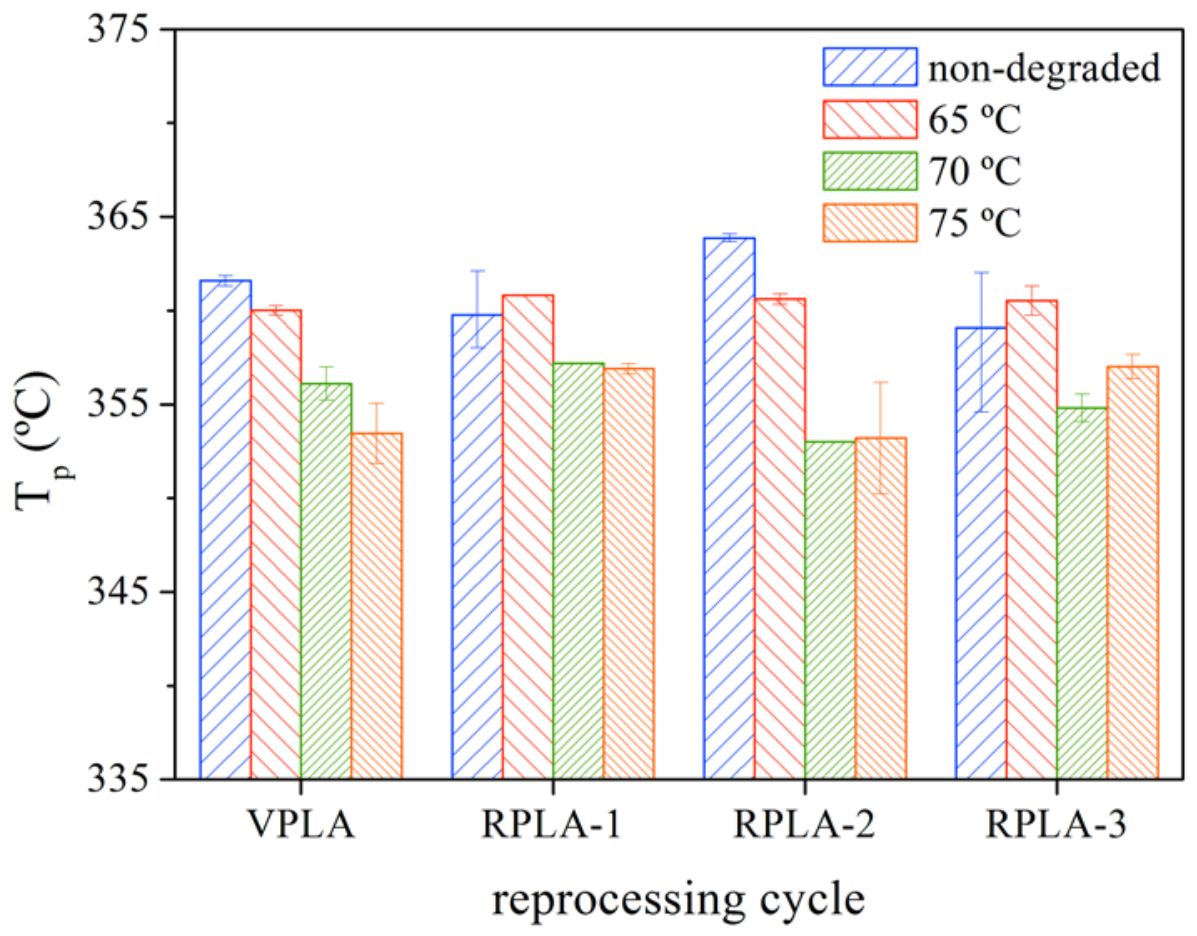


FIGURE 5

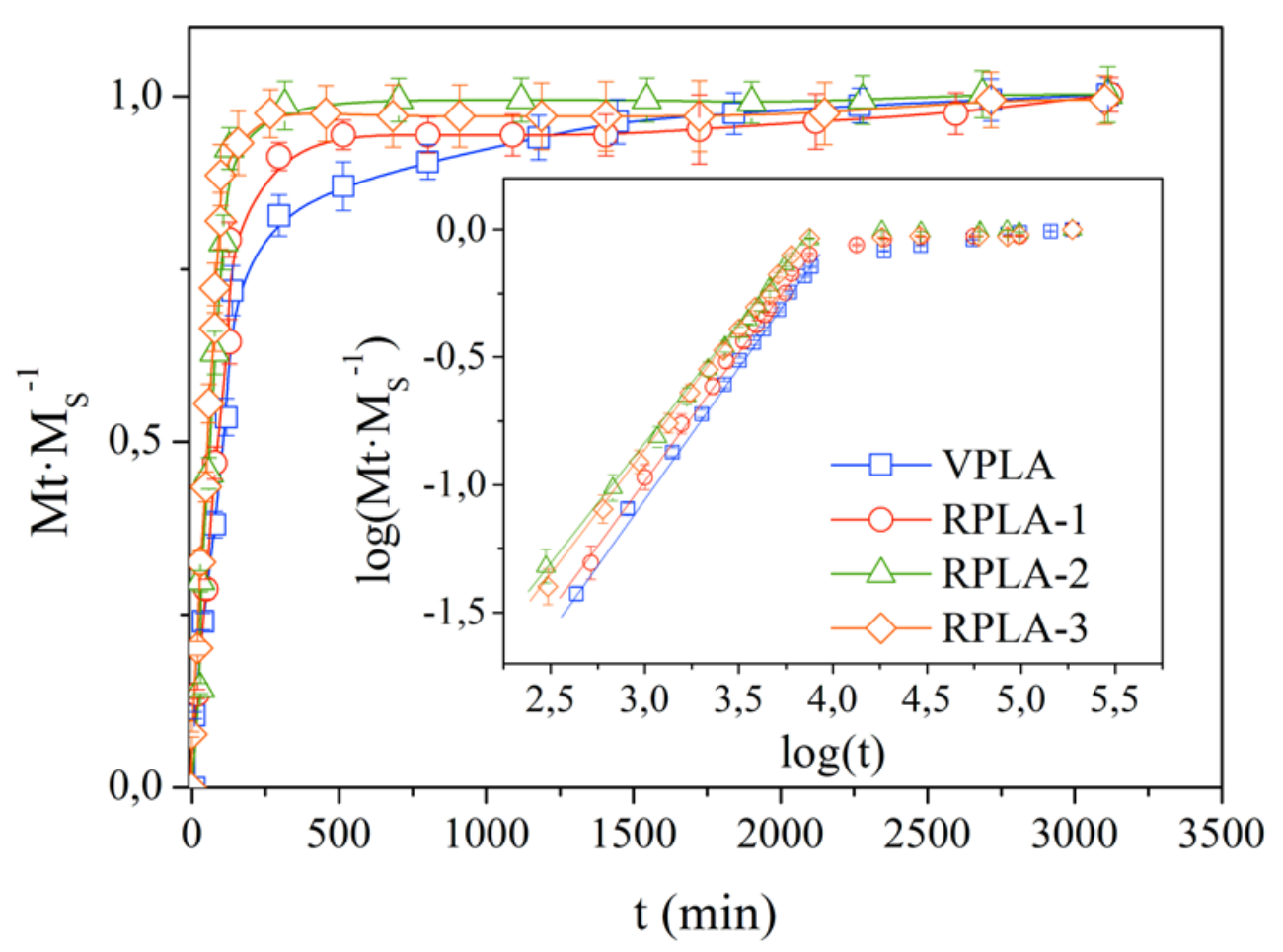




\section{FIGURE 6}

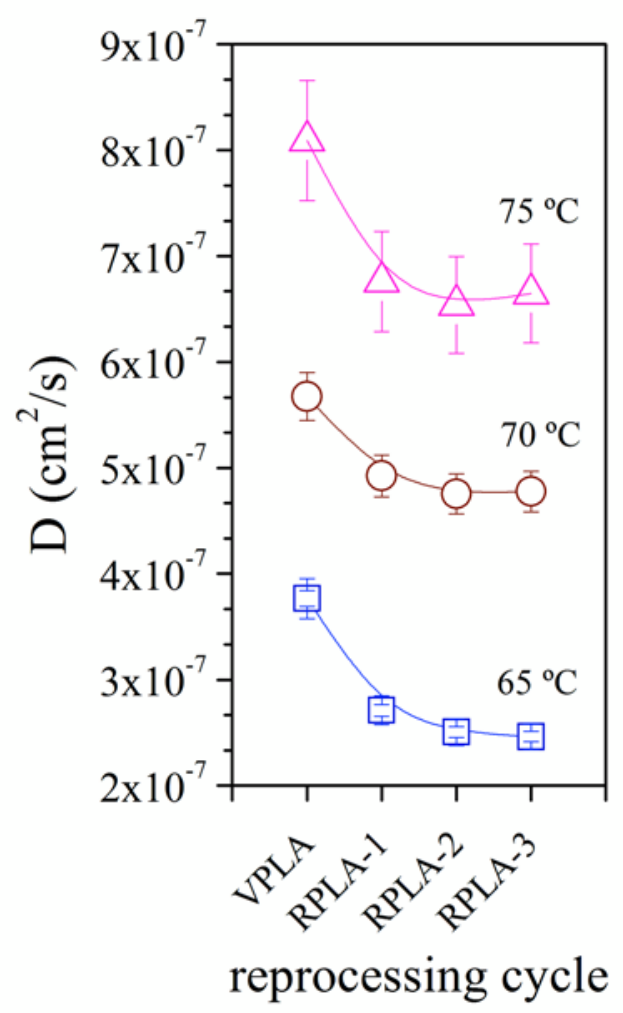




\section{FIGURE 7}

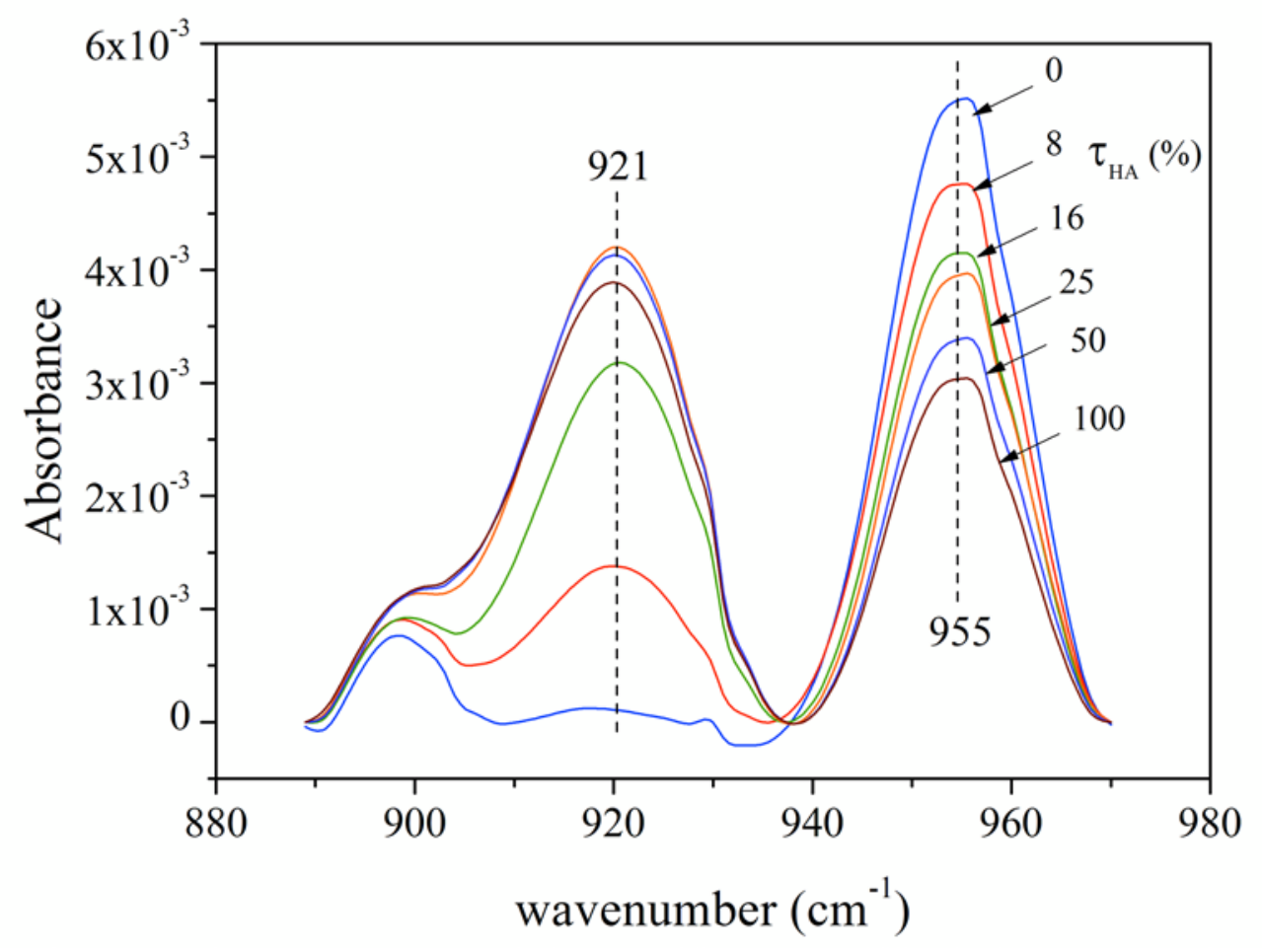


Badia, J. D., Santonja-Blasco, L., Martínez-Felipe, A., Ribes-Greus, A. (2012). Hygrothermal ageing of reprocessed polylactide. Polymer degradation and stability, 97(10), 1881-1890.

\section{FIGURE 8}
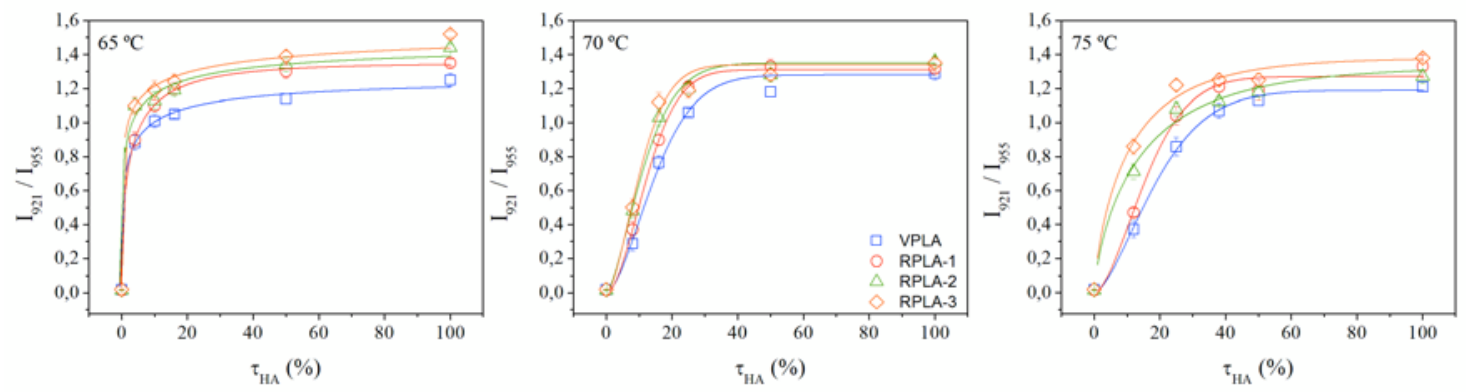
Badia, J. D., Santonja-Blasco, L., Martínez-Felipe, A., Ribes-Greus, A. (2012). Hygrothermal ageing of reprocessed polylactide. Polymer degradation and stability, 97(10), 1881-1890.

FIGURE 9 
Badia, J. D., Santonja-Blasco, L., Martínez-Felipe, A., Ribes-Greus, A. (2012). Hygrothermal ageing of reprocessed polylactide. Polymer degradation and stability, 97(10), 1881-1890.

\section{FIGURE 10}
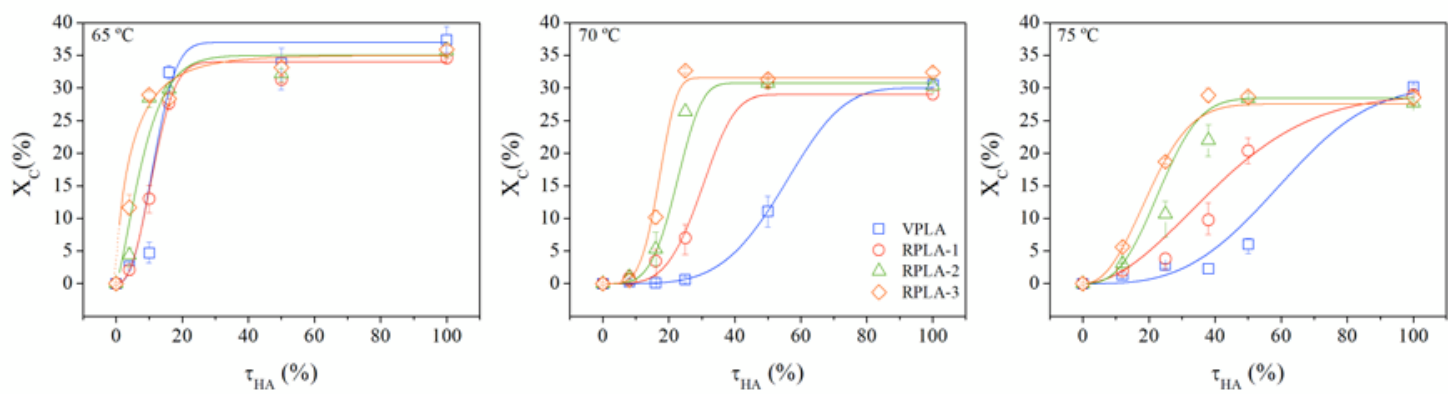
FIGURE 11

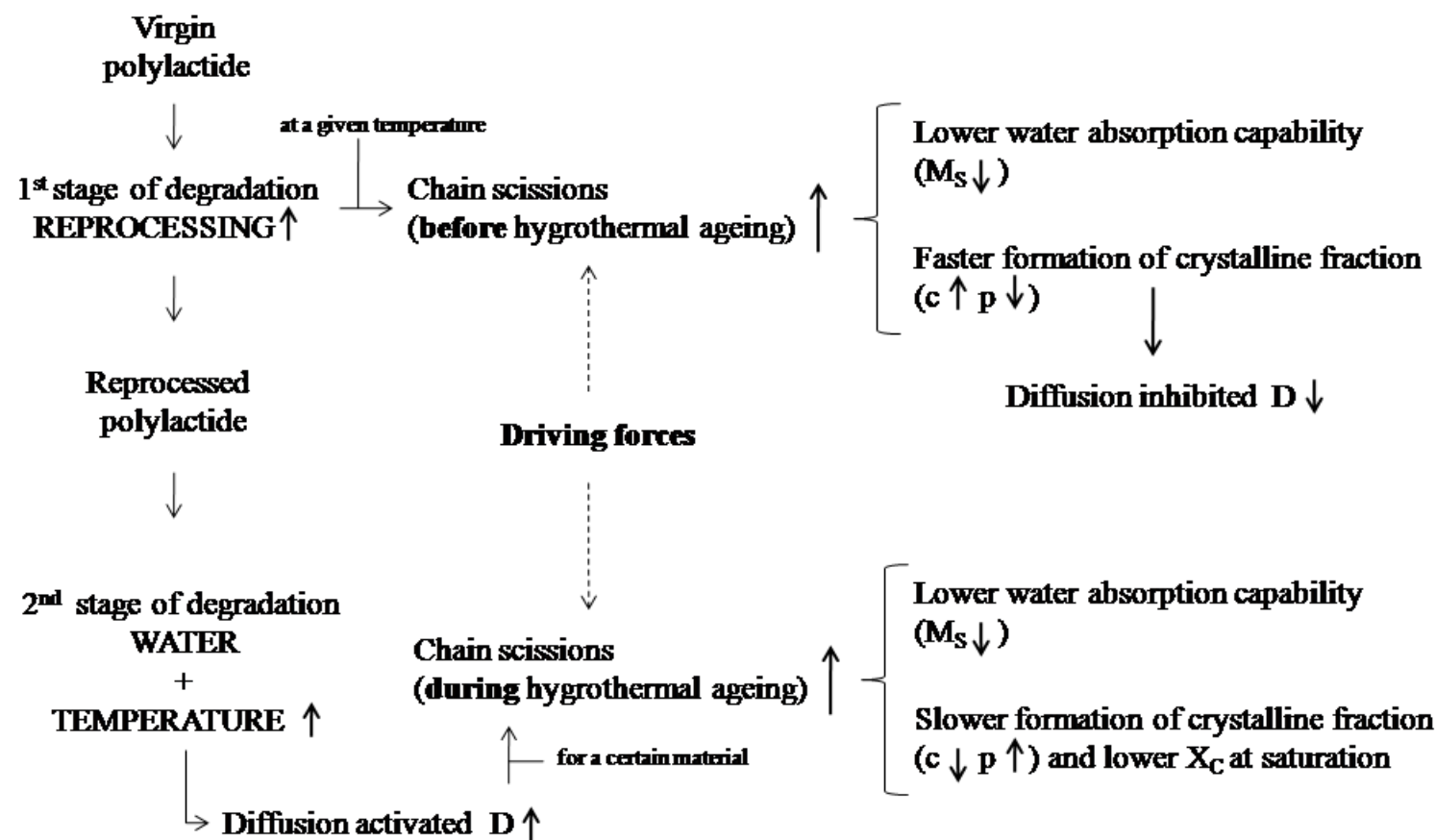




\section{Captions to tables}

Table 1. Mass uptake saturation points and relative variations for virgin and reprocessed PLA at all hygrothermal ageing temperatures.

Table2. Results of the application of Fickian kinetics to the water absorption behaviour of virgin and reprocessed PLA, according to Eq. (5).

Table3. Results of the fitting of the FT-IR indexes evolution to the Weibull model- Eq. (9)..

Table 4. Evolution of the characteristic temperatures obtained by DSC for virgin and reprocessed PLA.

Table 5. Results of the fitting of the crystallinity degree evolution to the Weibull model- Eq. (11). 
Badia, J. D., Santonja-Blasco, L., Martínez-Felipe, A., Ribes-Greus, A. (2012). Hygrothermal ageing of reprocessed polylactide. Polymer degradation and stability, 97(10), 1881-1890. 
Table 1

\begin{tabular}{|c|c|c|c|c|c|c|c|c|c|}
\hline & & & \multirow[t]{2}{*}{$M_{S}(\%)$} & \multicolumn{3}{|c|}{$T_{H A}\left({ }^{\circ} \mathrm{C}\right)$} & \multicolumn{3}{|c|}{ Relative variations (due to $\mathrm{T}_{\mathrm{HA}}$ ) } \\
\hline & & & & 65 & 70 & 75 & 65 to 70 & 70 to 75 & 65 to 75 \\
\hline & & & VPLA & $2.066 \pm 0.022$ & $1.619 \pm 0.028$ & $0.975 \pm 0.026$ & $-21,6 \%$ & $-39,8 \%$ & $-52,8 \%$ \\
\hline & & & RPLA-1 & $1.726 \pm 0.023$ & $1.362 \pm 0.024$ & $0.858 \pm 0.025$ & $-21,1 \%$ & $-37,0 \%$ & $-50,3 \%$ \\
\hline & & & RPLA-2 & $1.496 \pm 0.014$ & $1.298 \pm 0.017$ & $0.743 \pm 0.023$ & $-13,2 \%$ & $-42,8 \%$ & $-50,3 \%$ \\
\hline & & & RPLA-3 & $1.542 \pm 0.018$ & $1.220 \pm 0.017$ & $0.724 \pm 0.017$ & $-20,9 \%$ & $-40,7 \%$ & $-53,0 \%$ \\
\hline \multirow{5}{*}{ 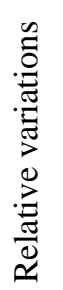 } & \multirow{5}{*}{\multicolumn{2}{|c|}{ 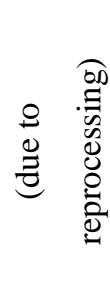 }} & VPLA to RPLA-1 & $-16,5 \%$ & $-15,9 \%$ & $-12,0 \%$ & & & \\
\hline & & & RPLA-1 to-RPLA-2 & $-13,3 \%$ & $-4,7 \%$ & $-13,4 \%$ & & & \\
\hline & & & RPLA-2 to RPLA-3 & $3,1 \%$ & $-6,0 \%$ & $-2,6 \%$ & & & \\
\hline & & & VPLA to RPLA-2 & $-27,6 \%$ & $-19,8 \%$ & $-23,8 \%$ & & & \\
\hline & & & VPLA to RPLA3 & $-25,4 \%$ & $-24,6 \%$ & $-25,7 \%$ & & & \\
\hline
\end{tabular}


Table 2

\begin{tabular}{|l|c|l|c|c|c|c|c|c|c|}
\hline \multirow{3}{*}{} & \multicolumn{9}{|c|}{$T_{H A}\left({ }^{\circ} \mathrm{C}\right)$} \\
\cline { 2 - 10 } & \multicolumn{3}{|c|}{65} & \multicolumn{3}{c|}{70} & & \multicolumn{3}{c|}{75} \\
\cline { 2 - 10 } & $n$ & $\log \left(\mathrm{k} / \mathrm{min}^{-1}\right)$ & $R^{2}$ & $n$ & $\log \left(\mathrm{k} / \mathrm{min}^{-1}\right)$ & $R^{2}$ & $n$ & $\log \left(\mathrm{k} / \mathrm{min}^{-1}\right)$ & $R^{2}$ \\
\hline VPLA & 1.021 & -4.089 & 0.998 & 0.850 & -2.935 & 0.998 & 0.968 & -3.210 & 0.999 \\
\hline RPLA-1 & 1.041 & -4.101 & 0.998 & 0.919 & -3.173 & 0.995 & 0.994 & -3.241 & 0.999 \\
\hline RPLA-2 & 0.915 & -3.598 & 0.999 & 0.815 & -2.822 & 0.991 & 0.959 & -3.127 & 0.996 \\
\hline RPLA-3 & 0.987 & -3.843 & 0.999 & 0.979 & -3.128 & 0.997 & 0.989 & -3.206 & 0.994 \\
\hline
\end{tabular}


Table 3

\begin{tabular}{|c|c|c|c|c|c|c|c|c|c|}
\hline & \multicolumn{9}{|c|}{$T_{H A}\left({ }^{\circ} \mathrm{C}\right)$} \\
\hline & \multicolumn{3}{|c|}{65} & \multicolumn{3}{|c|}{70} & \multicolumn{3}{|c|}{75} \\
\hline & C & $\mathrm{p}$ & $\mathrm{R}^{2}$ & C & $\mathrm{p}$ & $\mathrm{R}^{2}$ & C & $\mathrm{p}$ & $\mathrm{R}^{2}$ \\
\hline VPLA & $0.458 \pm 0.114$ & $0.32 \pm 0.04$ & 0.952 & $0.057 \pm 0.003$ & $1.63 \pm 0.23$ & 0.978 & $0.045 \pm 0.002$ & $1.55 \pm 0.12$ & 0.992 \\
\hline RPLA-1 & $0.476 \pm 0.041$ & $0.30 \pm 0.02$ & 0.993 & $0.067 \pm 0.002$ & $1.79 \pm 0.05$ & 0.969 & $0.053 \pm 0.003$ & $1.67 \pm 0.23$ & 0.972 \\
\hline RPLA-2 & $\begin{array}{l}0.549 \\
\sim\end{array}$ & $\sim 0.28$ & 0.899 & $0.075 \pm 0.003$ & $1.49 \pm 0.20$ & 0.975 & $0.064 \pm 0.007$ & $0.73 \pm 0.11$ & 0.938 \\
\hline RPLA-3 & $0.607 \pm 0.114$ & $0.23 \pm 0.02$ & 0.927 & $0.082 \pm 0.006$ & $1.53 \pm 0.31$ & 0.948 & $0.086 \pm 0.012$ & $0.75 \pm 0.14$ & 0.914 \\
\hline
\end{tabular}




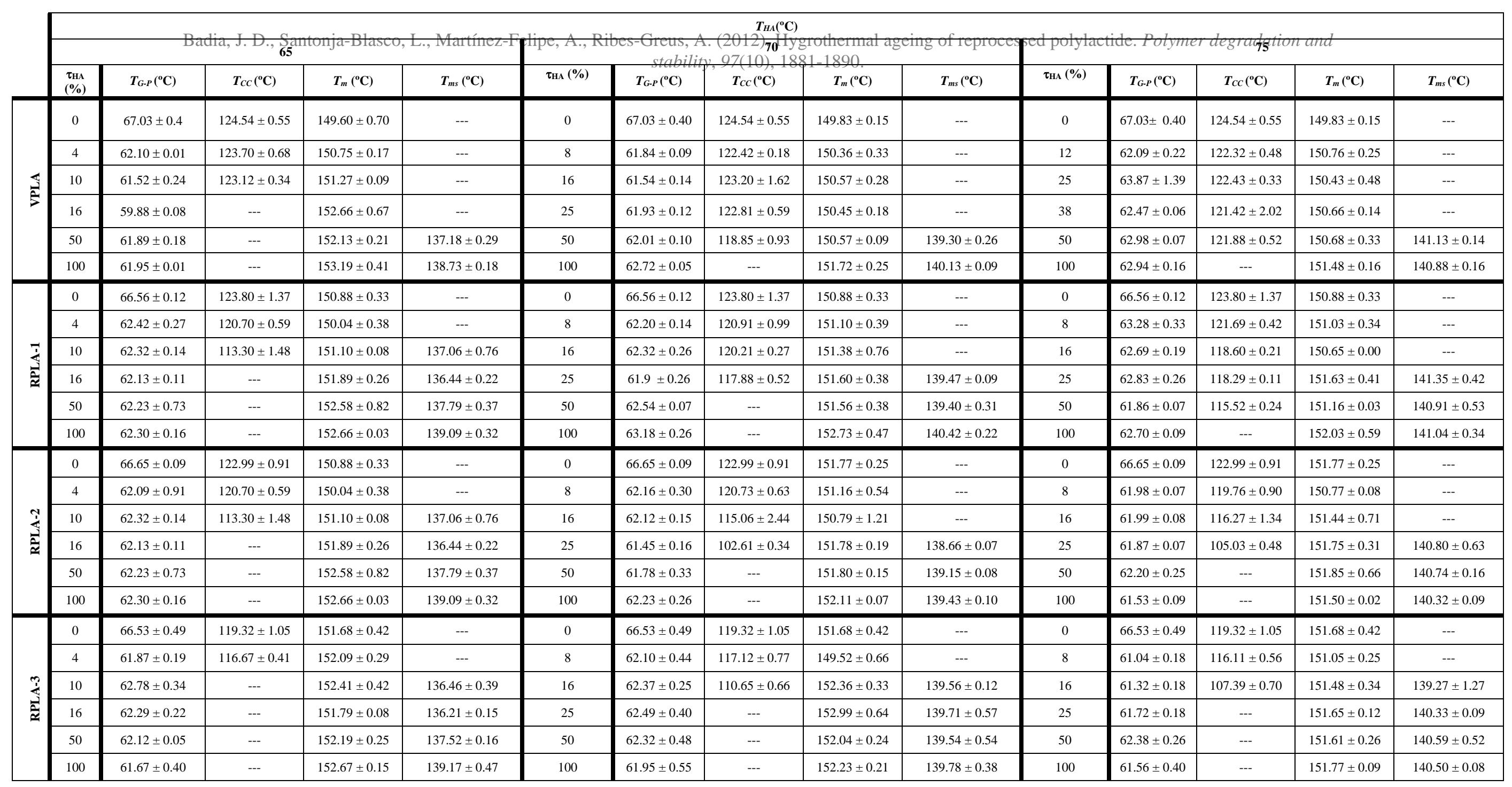

Table 4 
Badia, J. D., Santonja-Blasco, L., Martínez-Felipe, A., Ribes-Greus, A. (2012). Hygrothermal ageing of reprocessed polylactide. Polymer degradation and stability, 97(10), 1881-1890.

Table 5

\begin{tabular}{|c|c|c|c|c|c|c|c|c|c|}
\hline & \multicolumn{9}{|c|}{$T_{H A}\left({ }^{\circ} \mathrm{C}\right)$} \\
\hline & C & $\mathrm{p}$ & $\mathrm{R}^{2}$ & C & $\mathrm{p}$ & $\mathrm{R}^{2}$ & C & $\mathrm{p}$ & $\mathrm{R}^{2}$ \\
\hline VPLA & $0.075 \pm 0.009$ & $2.47 \pm 0.58$ & 0.936 & $0.016 \pm 0.001$ & $4.37 \pm 0.55$ & 0.998 & $0.015 \pm 0.002$ & $3.17 \pm 0.76$ & 0.973 \\
\hline RPLA-1 & $0.077 \pm 0.006$ & $2.34 \pm 0.55$ & 0.968 & $0.030 \pm 0.007$ & $4.23 \pm 0.21$ & 0.989 & $0.021 \pm 0.002$ & $2.92 \pm 0.14$ & 0.997 \\
\hline RPLA-3 & $\sim 0.177$ & $\sim 0.695$ & 0.789 & $0.054 \pm 0.003$ & $4.30 \pm 0.42$ & 0.972 & $0.042 \pm 0.001$ & $2.26 \pm 0.19$ & 0.991 \\
\hline
\end{tabular}

